\title{
Comparison of Ductoscopy, Galactography, and Imaging Modalities for the Evaluation of Intraductal Lesions: A Critical Review
}

\author{
Ozgur Sarica $^{a}$ Enis Ozturk ${ }^{b}$ Huseyin C. Demirkurek ${ }^{c}$ Fatih Uluc $^{a}$ \\ aDepartment of Radiology, Taksim Education and Research Hospital, \\ bDepartment of Radiology, Bakirkoy Education and Research Hospital, \\ 'Department of Nuclear Medicine, Taksim Education and Research Hospital, Istanbul, Turkey
}

\section{Keywords}

Ductoscopy · Imaging methods · Biopsy · Papilloma .

Ductal carcinoma

\section{Summary}

Background: Today, in cases of nipple discharge of unclear origin, the abundance of diagnostic procedures - a ,diagnostic dilemma' - becomes apparent, because unequivocal indications and a current, standardized examination sequence are presently not available. The diagnostic workup of patients with nipple discharge usually includes the clinical history, physical examination, mammography, ultrasonography, galactography, and nipple discharge cytology, but not ductoscopy. Methods: In this review we analyze and discuss the possible role of ductoscopy in evaluating intraductal pathologies and its combined use with diagnostic imaging modalities. For this purpose, we reviewed and compared the results of the radiological, pathological, and surgical studies independently. Conclusions: Currently, there is no solitary accurate modality to reach our definitive purpose. Being aware of the capability of each diagnostic modality may take us closer to our target. Therefore, adjunct and appropriate use of multiple imaging modalities and ductoscopy is necessary to evaluate patients with nipple discharge.

\author{
Schlüsselwörter \\ Duktoskopie - Bildgebungsverfahren - Biopsie · \\ Papillom · Duktuskarzinom
}

\section{Zusammenfassung}

Hintergrund: Derzeit wird in Fällen von Brustwarzensekretion unklarer Ursache die Fülle von diagnostischen Verfahren - ein "diagnostisches Dilemma» - deutlich, da eindeutige Indikationen und eine aktuelle standardisierte Untersuchungsabfolge zurzeit nicht zur Verfügung stehen. Die diagnostische Erfassung von Patientinnen mit Brustwarzensekretion umfasst normalerweise Anamnese, körperliche Untersuchung, Mammographie, Ultraschalluntersuchung, Galaktographie und zytologische Analyse des Brustwarzensekrets, aber keine Duktoskopie. Methoden: In dieser Übersichtsarbeit wird untersucht, welche Rolle die Duktoskopie bei der Evaluierung von intraduktalen Krankheitsbildern spielt, auch in Verbindung mit bildgebenden Verfahren. Zu diesem Zweck überprüften und verglichen wir die Ergebnisse der radiologischen, pathologischen und chirurgischen Studien unabhängig voneinander. Schlussfolgerungen: Zurzeit gibt es keine einzelne präzise Ausführungsart, die unser festgelegtes Ziel erreichen könnte. Das Bewusstsein für die Kapazität jeder der diagnostischen Ausführungsmöglichkeiten könnte uns dem Ziel ein Stück näher bringen. Deshalb ist die kombinierte und angemessene Anwendung von verschiedenen Bildgebungsarten zusammen mit der Duktoskopie notwendig, um Patienten mit Brustwarzensekretion zu evaluieren.

\section{KARGER \\ Fax +497614520714 \\ Information@Karger.com}

www.karger.com (c) 2013 S. Karger GmbH, Freiburg

1661-3791/13/0085-0348\$38.00/0

Accessible online at:

www.karger.com/brc
Dr. Ozgur Sarica

Taksim Education and Research Hospital

Department of Radiology

Prof. Hifzi Ozcan cd adalet sitesi

A blok Daire 13, Kucukbakkalkoy, Istanbul, Turkey

sozgur@yahoo.com 


\section{Introduction}

Until the 1950s, many mastectomies were performed unnecessarily without obtaining a histopathological diagnosis since nipple discharge was considered as a definite indicator of carcinoma of the breast. Subsequently, in the late 1980s, radiologists began percutaneous image-guided histological needle sampling of the breast, enabling an accurate, minimally invasive biopsy [1]. Despite the benign results of these biopsies, the possibility of high-risk lesions, ductal carcinoma in situ (DCIS) upgrade, and incomplete percutaneous excision indicates the continuing need for surgery.

Pathological nipple discharge (PND) is defined as spontaneous or easily expressible single-duct nipple discharge or any discharge that is grossly bloody [2]. With the efforts of researchers in the early 1990s, direct endoluminal visualization of the breast ducts has become possible [3]. In contrast to the initial rigid ductoscopes with a diameter of more than $1.5 \mathrm{~mm}$, rapidly developing technology has given us the opportunity to use fiberoptic ductoscopes with smaller diameters $(0.55$ $1.1 \mathrm{~mm}$ ) [4].

The diagnostic workup of patients with nipple discharge usually includes physical examination, mammography (MG), ultrasonography (US), galactography, and nipple discharge cytology. Few studies evaluated the results of the radiological diagnostic modalities in conjunction with mammary ductoscopy (MD). In this review, we analyze and discuss the possible role of ductoscopy in evaluating intraductal pathologies and its combined use with diagnostic imaging modalities.

\section{Ductoscopic Technique and Indications}

The endoscope is inserted through the ductal opening after dilating the duct with a suitable probe. Saline solution is injected through the working channel of the endoscope for clear visualization of the intraductal space [5] (fig. 1, online supplemental material www.karger.com/?DOI=000355833).

Although some reports claim that ductoscopy is technically possible not only in dilated but also in normal-caliber milk ducts [6], successful duct cannulation is achieved in $88-96 \%$ of patients $[7,8]$. Conventional galactography is technically inadequate in approximately $10 \%$ of patients [9]. Ductoscopy can fail in patients with inverted nipples, intolerable pain, narrow ducts, and a stricture or obstructing lesion near the nipple [7, 10]. Researchers were able to depict the lactiferous ducts up to $2-3.3 \mathrm{~cm}$ on average, whereby the greatest peripheral depth was $7.5-10 \mathrm{~cm}[6,8,11,12]$. On the other hand, some authors insist on the use of ductoscopy solely for central ducts $[13,14]$.

Breasts with spontaneous nipple discharge (SND) are more likely to contain an intraductal papilloma or hyperplasia secreting fluid and allowing the scope to travel further. For these patients, cannulation of the duct is not significantly affected by previous breast surgery [7]. Conversely, some authors state that compression by invasive carcinoma or previous biopsies prevents the scope from traveling deep into the breast [11]. Although some authors report that the flexible ductoscopes do not transgress the myoepithelial layer of the ductal system [15], perforation of the duct is a potential complication of galactography and ductoscopy [10]. Researchers observed no persistent pain, mastitis, subareolar inflammation, bleeding, nipple necrosis, or increase in nipple discharge following MD [7, 15].

A well-known clinical application of MD is PND. There are also some other indications such as determination of the surgical area before breast-conserving surgery and screening high-risk group patients. Some surgeons claimed that this would be a screening modality in the future.

The presence of extensive intraductal carcinoma is definitely a risk factor for surgical margin involvement. The reexcision rate for DCIS may be as high as $60 \%$ [16]. The extent of ductal involvement can be defined with MD, which makes MD a useful tool in planning breast-conserving surgery. Ductoscopy can detect additional lesions outside the scheduled lumpectomy site that were not visualized by MG and US [17]. However, in some contradictory studies, a significant number of these additional lesions were either benign or within the field of lumpectomy; thus, this procedure had no additional benefits $[18,19]$.

Annual magnetic resonance imaging (MRI) and $\mathrm{MG}$ is now the standard of care for screening high-risk patients [20]. However, MD is suggested as a risk assessment tool in some papers. Ductal lavage is currently being used in several centers to guide risk-reducing strategies in high-risk women [21]. When malignant cells are present in the lavage fluid, the diagnosis can be confirmed with MG, US, and/or MRI. If these investigations are negative for malignancy, then ductal imaging (galactography and/or MD) may be helpful [22]. However, in a recent study in asymptomatic, high-risk patients, there was poor concordance with histology and therefore the addition of ductoscopy added little to the evaluation. Histological atypia or malignancy identified by ductal lavage and ductoscopy was found in only 5 of 102 (5\%) high-risk women in the study, even though cytologic atypia was identified in $26 \%$ [23].

Some researchers supporting the sick-lobe hypothesis point out that ductoscopy can be used as a population-based screening modality in the future. Nevertheless, there are 2 problems. Primarily, it is not certain whether or not the ductoscopically examined lobe in the asymptomatic patient population is the real sick lobe. The second problem is that the addition of invasive procedures in screening protocols would lower the convenience rate in the follow-up of high-risk patients. 


\section{Ductoscopic Visual Diagnosis, Sensitivity, and Limitations}

According to some studies, the ductoscopic visual morphology of lesions can be classified as hemispheric, papillary, and flat protrusion type. The hemispheric and papillary shapes are the most common ones in cases of intraductal papilloma; however, the possibility of a malignancy in the multiple polypoid-type lesions should not be ignored. Histologically, yellow and ash-gray nodules are to be found as intraductal papillomas, whereas the red nodules are intraductal papillomas with hypervascularity and bleeding [24, 25]. Contrary to hemispheric and papillary shapes, the flat protrusion type is the most common one in cases of carcinoma [22]. In those cases, cancer arising from the mammary ducts appeared white in color and was described as slightly elevated [25].

The appearance of DCIS lesions is characterized by hemorrhagic, circumferentially obstructing, irregular fungating masses protruding into the lumen [15, 26]. A fibrous bridging structure is a product of inflammatory changes, and visualization of a ductal stricture commonly correlates with ductal hyperplasia [7]. Diffuse intraductal thickening corresponded to diffuse papillomatosis on histopathological analysis [26] (fig. 2, online supplemental material www.karger.com/ ?DOI=000355833).

There are contradictory views about the correlation between intraductal visual observations and histopathological diagnosis (table 1, online supplemental material www.karger.com/?DOI=000355833). While some researchers stated a significant correlation [27], others found no specific data, except for gross morphological abnormalities such as papillomas. Thus, visual inspection alone could not be sufficient to differentiate between benign and malign lesions [7, 10].

Ductoscopy allows the identification of intraluminal growths down to about $1 / 100 \mathrm{~mm}$. This resolution is far more superior to any other diagnostic imaging technique [16]. Small-sized papillomas might be occult on conventional MRI (fig. 3, online supplemental material www.karger.com/?DOI=000355833). Magnetic resonance galactography using a special microscopic coil (commercially available) can detect ducts measuring $0.8 \mathrm{~mm}$ and intraductal lesions as small as $1.0 \mathrm{~mm}$ [28] and can visualize both peripheral and proximal ducts, resulting in a higher probability of detecting additional intraductal lesions [29]. Debra Stick developed an intraductal radiofrequency microcoil that can provide microscale images [30].

Both ductoscopy and galactography have been reported to detect multiple lesions in $30 \%$ of patients with nipple discharge [15, 31] (fig. 4, online supplemental material www.karger.com/? DOI=000355833). An increased incidence in the development of cancer has been suggested particularly in patients with multiple papillomas [32]. Carcinoma was identified in $37.5 \%$ of cases that were associated with peripheral papillomas [33]. Matsugana et al. [34] showed the coexistence of intraductal papilloma in a major duct and ductal cancers separately in a peripheral duct. Denewer et al. [27] found that the ductoscopic distance traveled was significantly related to histopathology. They did not find any malignant lesion within a depth of $2 \mathrm{~cm}$. These deeper lesions can be missed by conventional major duct excision $[8,35]$. In patients with nipple discharge, the percentage of galactographically detected lesions deeper than $3 \mathrm{~cm}$ and ductoscopically detected lesions beyond $4 \mathrm{~cm}$ are $20 \%$ and $18 \%$, respectively $[5,31]$.

Technological advances in ductoscopy, such as autofluorescence techniques and molecular cytopathological and intraductal biopsy methods, are promising. Douplik et al. [36] have shown that autofluorescence ductoscopy could distinguish between tumor and normal tissue in an ex vivo setting. Cellular features such as DNA methylation analysis with cytomorphology may be helpful for increasing the sensitivity [37, 38]. Intraductal breast biopsy (IDBB) methods have not yet been standardized. In addition to the brush cytology method, there is another method that is used to obtain tiny tissue samples with a grasping basket or a metallic tube possessing a side aperture and which can provide adequate diagnostic information $[10,39]$. It is also conceivable to biopsy a ductoscopically discovered lesion with classical vacuum-assisted breast biopsy under combined sonographic-ductoscopic control.

\section{Sensitivity and Specificity}

Our literature survey showed us that only lesion determination rates were reported with ductoscopy. In contrast to diagnostic imaging modalities, which provide sensitivityspecificity results in the discrimination of benign-malign lesions, there were no papers reporting the use of ductoscopy in such discrimination; thus, it is not possible to make a meaningful meta-analysis comparing ductoscopy with radiological modalities.

Comparisons of the detection rate of intraductal abnormalities with galactography and ductoscopy were made in 3 studies (table 2, online supplemental material www.karger.com/ ?DOI=000355833). These studies emphasize that the use of ductoscopy eliminates the need for preoperative galactography. Ductoscopy allows a more precise localization of the lesion and also provides intraductal sampling of the ductal cells for cytological analysis. In some cases, the results of both methods were complementary. In 2 studies, intraductal lesions that were not reached by ductoscopy could be shown by galactography [10, 39].

The sensitivity and specificity results of conventional imaging methods from the surgical and radiological literature show some differences in terms of determining malignancy in patients with nipple discharge. In order to be able to do an unbiased review, many articles from both disciplines were included in table 3 (online supplemental material 
www.karger.com/?DOI=000355833), aiming to reach a broader range.

In a study published by Shen et al. [15] on 157 operated patients, the overall positive predictive value of MD screening was found to be $83 \%$, with no benign and malignant discrimination. When combined with a cytological analysis of the endoscopic lavage of the ducts, this figure improved to $86 \%$. Negative predictive values, sensitivity, and specificity were reported as 82,88 , and $77 \%$, respectively. Vaughan et al. [2] reported lower rates in 89 patients undergoing intraoperative ductoscopy and having duct excisions. If visualization of a papillary lesion was considered as a positive visual ductoscopic finding, the sensitivity and specificity of ductoscopy for pathologically proven papillomas were 73 and $56 \%$, respectively. If visualized webs, abnormal discharge, bleeding, and abnormal linings were considered as positive findings, the sensitivity increased to 89 whereas specificity decreased to $20 \%$.

Success of MRI is not clear enough in patients with nipple discharge. In the initial studies with limited data, some authors concluded that MRI may help to distinguish between benign and malignant causes of nipple discharge [58, 59]. Morrogh et al. [46] proposed that the sensitivity and specificity of MRI were $70 \%$ and 44, respectively, when performed after negative standard evaluation in their study in 2010. Lorenzon et al. [41] retrospectively evaluated 38 patients with PND by MG, US, and MRI. They found that sensitivity and specificity of MRI were 94.7 and $78.9 \%$, respectively. In comparison to US and MG, MRI has shown statistically significantly higher overall sensitivity and specificity (OSS) values. In a 2012 study comprising 94 patients with nipple discharge, only 12 patients were evaluated with MRI. In this study, there was no statistically significant difference between MRI and the combination of ductography and sonography [43]. However, in a different study, El Khoury et al. [60] concluded that occult malignancy with the standard modalities could be detected by MRI in 3 of $36(8 \%)$ patients.

In patients with nipple discharge, the rates of invasive and in situ diseases are equal to each other or in favor of DCIS [35, 45, 47, 51]. Breast MRI has a high sensitivity for non-invasive disease especially for high-grade DCIS, in which its sensitivity reaches $87 \%$ [61]. The detection rate of MRI for small focal intraductal lesions is lower than of ductography and sonography, but it is the most effective modality for detecting high-grade DCIS. Sabel et al. [62] stated that a negative MRI result in addition to negative conventional imaging would further reduce the probability of malignancy. On the other hand, false-positive MRI results may increase the biopsy rates. In a study of Fisher and Margenthaler [63], 4 of the 7 patients with DCIS underwent MRI after the duct excision and 3 of the 4 had non-mass-like enhancement suggestive of extensive DCIS. None of the patients with DCIS underwent preductoscopic MRI, but all had Breast Imaging Report and Data System (BI-RADS) category I/II/III breast imaging.
Nelson and Hoehn [64] concluded that central duct resection (CDR) is an effective way for the removal of malignancy without leaving a residual pathology in the diagnosis and treatment of PND. Besides, Carty et al. [65] found no malignancy in a 5-year follow-up of 49 patients whose physical examinations, imaging, and cytological findings were negative. In a mean follow-up of 2 years, Gray et al. [66] visualized no cancer cases in 57 patients whose imaging findings were normal. The available limited number of publications indicates that the probability of a carcinoma is $0-5 \%$ in PND cases that are clinically and radiologically negative [35, 67]. Concerning the appropriate diagnostic and treatment approach, the uncertainty remains for which cases MG and US do not report any pathological lesions; however, in this special patient group, surgery and close follow-up options could be combined in existing algorithms $[4,35]$.

It is very difficult to set the exact positions of MRI and ductoscopy in patients with PND because ductoscopic studies are not widely approved in the surgical literature and there are so far no prospective trials to evaluate the role of MRI.

\section{Discussion and Conclusions}

Since $85 \%$ or more of breast cancers originate in the epithelial lining of mammary ducts from morphologically identifiable precursor lesions, MD can potentially detect breast cancer several years before detection by MG [68]. In clinical practice, palpable breast masses are usually about $1 \mathrm{~cm}$ in diameter; on the other hand, they are usually $0.5-1 \mathrm{~cm}$ when detected on MG [36]. The mean sojourn time (MST) is the preclinical detectable phase, i.e. the time difference between mammographic and clinical detectability. In other words, the MST is an expression of the tumor growth rate (grade 2 ductal, 3.0 years; grade 3 ductal, 3.1 years; DCIS, 5.1 years) [69]. Regarding these tumor growth rates, MD may detect small-sized (under $0.5-1 \mathrm{~cm}$ ) intraductal tumors 3 to 5 years earlier than MG. In a mean 22-year follow-up of 56 patients who underwent CDR for pathologic nipple discharge, only 3 of the patients ( $5 \%$ ) developed breast cancer (1 lobular, 1 invasive ductal, and 1 DCIS) on the same side of resection. They presumed that, if malignancy or premalignancy had been missed at the time of CDR, it would have been identified within the 15-year time frame [64].

We believe that the potential advantages of ductoscopy, which is offered instead of imaging modalities, were overexpressed in the surgical literature since the optimal modality was not chosen for comparison in patients with PND. As an example, Shen et al. [26] concluded that more than $50 \%$ of the patients with nipple discharge who had a DCIS lesion visible on MD and/or detectable by ductal lavage had a negative mammogram. Similarly, Kapenhas-Valdes et al. [16] also found that 5 patients $(8.8 \%)$ who were found to have carci- 
noma (one of them had invasive cancer and the remaining ones had DCIS or LCIS) with ductoscopy-guided cytopathology had benign and stable findings via breast imaging (MG and US). The accuracy of US and MG is 61 and $22 \%$, respectively, for noncomedo DCIS [70]. MG, US, and routine touch cytology of the nipple discharge are not sensitive in detecting DCIS. MRI should be considered as an alternative method for patients with high-grade DCIS because of its high sensitivity rates $(87 \%)$ [61].

In the surgical literature, many papers comparing screening MG and ductoscopy - which has not yet been approved as a screening tool - emphasize that diagnostic imaging modalities are inadequate to detect cancer because of the missed lesions at screening MG. Since screening is a different entity than diagnosing, such arguments may underestimate the capability of multi-modality diagnostic imaging. A study in the surgical literature states that only $4.3 \%$ of patients with pathologic discharge had normal findings with adjunct use of physical examination and imaging studies that consist of MG, sonography, and galactography [35].

Our aim is to find a method detecting all lesions, definitely differentiating between benign and malignant pathologies, ceasing nipple discharge, and excising lesions completely while protecting the anatomical integrity. Eventually, this application should be a method that does not need any supplementary modalities.

\section{Can Ductoscopy Detect All Lesions?}

Two studies proved that 60.4 [71] and 38.5\% [72] of papilloma (intraductal papilloma, IP) patients were asymptomatic either for nipple discharge or palpable mass. While only discharged ducts are cannulated by ductoscopy, radiological modalities can detect even intraductal lesions without discharge in asymptomatic patients. 2 studies that examined mastectomy specimens reported that $14-30 \%$ of intraductal carcinomas did not have the in situ component $[14,73]$. These observations raise the possibility that a significant percentage of patients undergoing surgery would not have an intraductal component and therefore MD would not be able to directly visualize some intraductal lesions.

Sauter et al. [74] demonstrated that 3 women with breast cancer had positive nipple aspirate fluid (NAF) cytology but negative MD samples. This was not surprising since NAF is often derived from several ducts, and the duct which was scoped might not have been the one containing the neoplastic cells.

\section{Can Ductoscopy Make Definitive Histopathological}

Diagnosis and Differentiate Early Signs of Malignancy without Any Need for Other Diagnostic Modalities?

Of the 14 studies analyzed by a recent paper, 8 studies suggest the routine excision of all papillomas (with or without atypical ductal hyperplasia $(\mathrm{ADH})$ ) because of high malignancy upgrade rates by core needle biopsy [75].
It is often difficult to collect adequate diagnostic specimens with IDBB because early-stage cancer may be located peripherally and not reached by MD. IDBB provided a definite diagnosis of carcinoma in $42.9 \%$ of carcinoma cases [34]. Due to the difficulty in obtaining diagnostic specimens with IDBB, ductoscopically guided ductal lavage cytology is more sensitive and complementary to IDBB.

According to many studies, after duct excision surgery, PND patients with an initial pathological diagnosis of 'benign or no abnormal findings' developed breast cancer [76, 77]. Ductoscopic follow-up is controversial because of its high false-positive rate reaching 17\% [7]. Large-scale ductoscopic follow-up protocols similar to radiological follow-up protocols have not yet been established. There is no study in the literature stating a false-negative malignancy rate by ductoscopic follow-up.

\section{Can IDBB Completely Excise All Lesions and Cease}

Discharge?

Although complete removal of some solitary papillomas by IDBB was reported in a study by Kamali et al. [10], approximately half of the papillomas could only be excised partially. Cessation of nipple discharge (the therapeutic effectiveness) after the IDBB was found in $78.1 \%$ of intraductal papilloma patients who were followed for more than 3 years [34]. On the other hand, we know that $80-97 \%$ of cases with clinical signs of discharge were resolved after 11-G mammotome biopsies $[78,79]$. It is not yet known whether short- or long-term success in curing recurrent discharge is more a function of duct disruption, lesion removal, or both.

\section{Can Ductoscopy Conserve the Anatomical Integrity by \\ Being Minimally Invasive and Prevent Excision of Benign Pathologies?}

The false-negativity rate of MD was determined to be $18 \%$. In half of these cases, the papillary alterations were small papillomas involving small to medium-sized ducts and in the other half there was diffuse papillomatosis [15]. Some surgeons state that the use of routine galactography or ductoscopy to select operative candidates is unnecessary because nearly all patients require surgical excision. Conversely, some reports claim that with the high specificity (91\%) of negative ductal washings combined with negative ductoscopy, in the absence of a demonstrable lesion, patients with nipple discharge can be spared from surgery [2]. Around $90 \%$ of patients with classic symptoms of PND who undergo ductoscopy-directed duct excision are found to have proliferative lesions in their duct excision specimens [2]. From this point of view, ductoscopy can reduce the size and number of open biopsies for PND; however, randomized controlled trials with long-term follow-up are warranted. 


\section{Conclusion}

Developments in autofluorescence techniques and molecular cytopathological methods are promising in terms of increasing the value of ductoscopy. However, in spite of such technological advances, there is no solitary accurate modality to reach our definitive purpose for the time being. Being aware of the capability of each diagnostic modality may take us closer to our target. Hence, adjunct and appropriate use of multiple imaging modalities and ductoscopy is necessary to evaluate patients with PND.

\section{Online Supplemental Material}

Table 1. Endoscopic classification of intraductal lesions

Table 2. Comparison of detection rates of intraductal abnormalities with galactography and ductoscopy

Table 3. Comparison of malignant lesion (cancer) detection rates in patients with PND for all diagnostic modalities and cytologic analysis, with the exception of ductoscopy, which determines the lesions but cannot make the benign-malignant discrimination
Fig. 1. The fiberoptic ductoscope and related equipment (courtesy of Omer Bender).

Fig. 2. Images from MD showing (A) a normal duct, (B) a large papilloma with hemorrhage, (C) slightly exophytic DCIS lesions, (D) a raspberry-like papilloma, (E) a papilloma with lobulated surface, $(\mathbf{F})$ a huge papilloma with irregular hemorrhagic surface (courtesy of Omer Bender).

Fig. 3. MRI appearances of a periareolar papilloma with a dimension of $5 \times 6 \mathrm{~mm}$.

Fig. 4. Intraductal filling defects visualized by galactography.

To access the online supplemental material please refer to www.karger.com/?DOI=000355833.

\section{Disclosure Statement}

The authors declare that they had no sources of support and that there are no conflicts of interest.

\section{References}

1 Jackman RJ, Burbank F, Parker SH, et al.: Atypical ductal hyperplasia diagnosed at stereotactic breast biopsy: improved reliability with 14-gauge, directional, vacuum-assisted biopsy. Radiology 1997;204:485-488

2 Vaughan A, Crowe JP, Brainard J, et al.: Mammary ductoscopy and ductal washings for the evaluation of patients with pathologic nipple discharge. Breast J 2009;15:254-260.

3 Berna JD, Gracia-Medina V, Kuni CC: Ductoscopy: a new technique for ductal exploration. Eur J Radiol 1991;12:127-129.

4 Hahn MT, Fehm EF, Solomayer KC, Siegmann AS, et al.: Selective microdochectomy after ductoscopic wire marking in women with pathological nipple discharge. BMC Cancer 2009;9:151.

$\checkmark 5$ Mokbel K, Elkak AE: The evolving role of mammary ductoscopy. Curr Med Res Opin 2002;18:3032.

6 Kothari A, Beechey-Newman N, Kulkarni D: Breast duct micro-endoscopy: a study of technique and a morphological classification of endoluminal lesions. Breast 2006;15:363-369.

7 Dietz JR, Crowe JP, Grundfest S, et al.: Directed duct excision by using mammary ductoscopy in patients with pathological nipple discharge. Surgery 2002;132:582-588.

8 Dooley WC: Routine operative breast endoscopy for bloody nipple discharge. Ann Surg Oncol 2002; 9:920-923.

-9 Koskela A, Berg M, Pietiläinen T, et al.: Breast lesions causing nipple discharge: preoperative galactography-aided stereotactic wire localization. AJR Am J Roentgenol 2005;184:1795-1798.

10 Kamali S, Bender O, Aydin MT, et al.: Ductoscopy in the evaluation and management of nipple discharge. Ann Surg Oncol 2010;17:778-783.

11 Sauter ER, Ehya H, et al.: Fiberoptic ductoscopy findings in women with and without spontaneous nipple discharge. Cancer 2005;103:914-921.
12 Grunwald S, Heyer H, Paepke S, et al.: Diagnostic value of ductoscopy in the diagnosis of nipple discharge and intraductal proliferations in comparison to standard methods. Onkologie 2007;30:243248.

13 Matsunaga T, Ohta D, Misaka T, Hosokawa K, Fujii M, Nakayama S, Kaise H, Kusama M, Koyanagi Y: Mammary ductoscopy for diagnosis and treatment of intraductal lesions of the breast. Breast Cancer 2001;8:213-221.

14 Badve S, Wiley E, Rodriguez N: Assessment of utility of ductal lavage and ductoscopy in breast cancer - a retrospective analysis of mastectomy specimens. Mod Pathol 2003;16:206-209.

15 Shen KW, Wu J, Lu JS, et al.: Fiberoptic ductoscopy for patients with nipple discharge. Cancer 2000;89:1512-1519.

16 Kapenhas-Valdes E, Feldman SM, Boolbol SK: The role of mammary ductoscopy in breast cancer; a review of the literature. Ann Surg Oncol 2008; 15:3350-3360.

17 Dooley WC: Routine operative breast endoscopy during lumpectomy. Ann Surg Oncol 2003;10:3842.

18 Kim JA, Crowe JP, Woletz J, et al.: Prospective study of intraoperative mammary ductoscopy in patients undergoing partial mastectomy for breast cancer. Am J Surg 2004;188:411-414.

19 Louie LD, Crowe JP, Dawson AE, Lee K, Baynes DL, Dowdy A, Kim JA: Identification of breast cancer in patients with pathologic nipple discharge: does ductoscopy predict malignancy? Am J Surg 2006;192:530-533.

20 Warner E: The role of magnetic resonance imaging in screening women at high risk of breast cancer. Top Magn Reson Imaging 2008;9:163-169.

21 Hollingsworth AB, Singletary SE, Morrow M, et al.: Current comprehensive assessment and management of women at increased risk for breast cancer. Am J Surg 2004;187:349-362.
22 Mokbel K, Escobar PF, Matsunaga T: Mammary ductoscopy: current status and future prospects. Eur J Surg Oncol 2005;31:3-8.

23 Cyr AE, Margenthaler JA, Conway J, et al.: Correlation of ductal lavage cytology with ductoscopy-directed duct excision histology in women at high risk for developing breast cancer: a prospective, single-institution trial. Ann Surg Oncol 2011; 18:3192-3197.

24 Makita M, Akiyama F, Gomi N, et al.: Endoscopic classification of intraductal lesions and histological diagnosis. Breast Cancer 2002;9:220-225.

25 Okazaki A, Okazaki M, Asaishi K, et al.: Fiberoptic ductoscopy of the breast: a new diagnostic procedure for nipple discharge. Jpn J Clin Oncol 1991;21:188-193.

26 Shen KW, Wu J, Lu JS, et al.: Fiberoptic ductoscopy for breast cancer patients with nipple discharge. Surg Endosc 2001;15:1340-1345.

27 Denewer A, El-Etribi K, Nada N, et al.: The role and limitations of mammary ductoscope in management of pathologic nipple discharge. Breast $\mathrm{J}$ 2008;14:442-449.

28 Kanemaki Y, Kurihar Y, Itoh D, et al.: MR mammary ductography using a microscopy coil for assessment of intraductal lesions. AJR Am J Roentgenol 2004;182:1340-1342.

29 Bhattarai N, Kanemaki Y, Kurihara Y, Nakajima Y, Fukuda M, Maeda I: Intraductal papilloma: features on MR ductography using a microscopic coil. AJR Am J Roentgenol 2006;186:44-47.

- 30 Rochman S, Mills D, Kim J, Kuerer H, Love S: Meeting report. State of the science and the intraductal approach of breast cancer. Proceedings summary of the 6. international symposium on the in traductal approach to breast cancer, Santa Monica, CA, USA, BMC Proceedings 2009;3(suppl 5):11.

31 Dawes LG, Bowen C, Venta LA, Morrow M Ductography for nipple discharge: replacement for ductal excision. Surgery 1998;124:685-691. 
-32 Carter D: Intraductal papillary tumors of the breast. Cancer 1977;39:1689-1692.

33 Ohuchi N, Abe R, Kasai M: Possible cancerous change of intraductal papilloma of the breast. Cancer 1984;54:605-611.

-34 Matsunaga T, Takeharu M, Katsumasa H, et al.: Intraductal approach to the detection of intraductal lesions of the breast. Breast Cancer Res Treat 2009;118:9-13.

35 Cabioglu N, Hunt KK, Singletary SE, et al.: Surgical decision making and factors determining a diagnosis of breast carcinoma in women presenting with nipple discharge. J Am Coll Surg 2003;196: 354-364.

36 Douplik A, Leong WL, Easson AM, et al.: Feasibility study of autofluorescence mammary ductoscopy. J Biomed Opt 2009;14:044036.

$\checkmark 37$ Khan SA, Mangat A, Rivers A, et al.: Office ductoscopy for surgical selection in women with pathologic nipple discharge. Ann Surg Oncol 2011;18:3785-3790.

\38 Fackler MJ, Rivers A, Teo WW, Mangat A, Taylor E, Zhang Z, et al.: Hypermethylated genes as biomarkers of cancer in women with pathologic nipple discharge. Clin Cancer Res 2009;15:38023811.

39 Hunerbein M, et al.: Ductoscopy and intraductal vacuum assisted biopsy in women with pathologic nipple discharge. Breast Cancer Res Treat 2006; 99:301-307.

40 Yamamoto D, Shoji T, Kawanishi H, Nakagawa H, Haijima H, Gondo H, Tanaka K: A utility of ductography and fiberoptic ductoscopy for patients with nipple discharge. Breast Cancer Res Treat 2001;70:103-108.

41 Lorenzon M, Zuiani C, Linda A, et al.: Magnetic resonance imaging in patients with nipple discharge: should we recommend it? Eur Radiol 2011;21:899-907.

42 Simmons R, Adamovich T, Brennan M, Christos P, Schultz M, Eisen C, Osborne M: Nonsurgical evaluation of pathologic nipple discharge. Ann Surg Oncol 2003;10:113-116.

43 Gonzalez P, Whitman G, Dryden M, Liu P, Dogan B: Is ductography still warranted in the 21st century? AJR Am J Roentgenol 2012;198(suppl 5): abstr. no. 140-149.

44 Deshmane VH, Mulani S, Lodh N, Pungavkar S, et al.: Correlation of mammography, ultrasound and MRI in patients with nipple discharge. Cancer Res 2011;71(suppl):abstr P2-08-11.

45 Adepoju LJ, Chun J, El-Tamer M, Ditkoff BA, Schnabel F, Joseph KA: The value of clinical characteristics and breast-imaging studies in predicting a histopathologic diagnosis of cancer or high-risk lesion in patients with spontaneous nipple discharge. Am J Surg 2005;190:644-646.

46 Morrogh M, Park A, Elkin B, et al.: Lessons learned from 416 cases of nipple discharge of the breast. Am J Surg 2010;200:73-80.

47 Morrogh M, Morris EA, Liberman L, et al.: The predictive value of ductography and magnetic reso- nance imaging in the management of nipple discharge. Ann Surg Oncol 2007;14:3369-3377.

48 Bauer R, Eckhert K, Nemoto T: Ductal carcinoma in situ-associated nipple discharge: a clinical marker for local extensive disease. Ann Sur Oncol 1998;5:452-455.

49 Daniel BL, Gardner RW, Birdwell RL, Nowels KW, Johnson D: Magnetic resonance imaging of intraductal papilloma of the breast. Magn Reson Imaging 2003;21:887-892.

50 Montroni I, Santini D, Zucchini G, et al.: Nipple discharge: is its significance as a risk factor for breast cancer fully understood? Observational study including 915 consecutive patients who underwent selective duct excision. Breast Cancer Res Treat 2010;123:895-900.

51 Florio MG, Manganaro T, Pollicino A, Scarfo P, Micali B: Surgical approach to nipple discharge: a ten-year experience. J Surg Oncol 1999;71:235-238.

52 Baitchev G, Gortchev G, Todora A, Dikov D, Stancheva N, Daskalova I: Intraductal aspiration cytology and galactography for nipple discharge. Int Surg 2003;88:83-86.

53 Dinkel HP, Gassel AM, Muller T, Lourens S, Rominger M, Tschammler A: Galactography and exfoliative cytology in women with abnormal nipple discharge. Obstet Gynecol 2001;97:625-629.

54 Sauter ER, Ehya H, Klein-Szanto AJ, WagnerMann C, Macgibbon B, Ehya H: Nipple aspirate fluid and ductoscopy to detect breast cancer. Diagn Cytopathol 2009;38:244-251.

55 Kooistra BW, Wauters C, van de Ven S, et al.: The diagnostic value of nipple discharge cytology in 618 consecutive patients. Eur J Surg Oncol 2009;35:573-577.

56 Lee WY: Cytology of abnormal nipple discharge: a cyto-histological correlation. Cytopathology 2003; 14:19-26.

57 El-Daly H, Gudi M: Evaluation of nipple discharge cytology and diagnostic value of red blood cells in cases with negative cytology: a cytohistologic correlation. Acta Cytol 2010;54:560-562.

58 Orel SG, Dougherty CS, Reynolds C, et al.: MR imaging in patients with nipple discharge: initial experience. Radiology 2000;216:248-254.

59 Nakahara H, Namba K, Watanabe R, et al.: A comparison of MR imaging, galactography and ultrasonography in patients with nipple discharge. Breast Cancer 2003;10:320-329.

60 El Khoury M, Lalonde L, David J, Labelle M, Trop I: Is breast MRI useful in the management of a nipple discharge? AJR Am J Roentgenol 2012;198(suppl 5):E013.

61 Kuhl CK, Schrading S, Bieling HB, Wardelmann E, Leutner CC, Koenig R, Kuhn W, Schild HH: MRI for diagnosis of pure ductal carcinoma in situ: a prospective observational study. Lancet 2007;370: 485-492.

62 Sabel MS, Helvie MA, Breslin T, et al.: Is duct excision still necessary for all cases of suspicious nipple discharge? Breast J 2012;18:157-162.
63 Fisher CS, Margenthaler JA: A look into the ductoscope: its role in pathologic nipple discharge. Ann Surg Oncol 2011;18:3187-3191.

64 Nelson RS, Hoehn JL: Twenty-year outcome following central duct resection for bloody nipple discharge. Ann Surg 2006;243:522-524.

65 Carty NJ, Mudan SS, Ravichandran D, et al.: Prospective study of outcome in women presenting with nipple discharge. Ann R Coll Surg Engl 1994; 76:387-389.

66 Gray RJ, Pockaj BA, Karstaedt PJ: Navigating murky waters: a modern treatment algorithm for nipple discharge. Am J Surg 2007;194:850-855.

67 Richards T, Hunt A, Courtney S, Umeh H: Nipple discharge: a sign of breast cancer? Ann R Coll Surg Engl 2007;89:124-126.

68 Going JJ, Moffat DF: Escaping from flatland: clinical and biological aspects of human mammary duct anatomy in three dimensions. J Pathol 2004; 203:538-544.

69 Tabar L: Teaching Course in Diagnostic Breast Imaging. Cave Creek, Mammography Education Inc, 2004.

70 Uematsu T, Yuen S, Kasami M, et al.: Comparison of magnetic resonance imaging, multidetector row computed tomography, ultrasonography, and mammography for tumour extension of breast cancer. Breast Cancer Res Treat 2008;112:461-474.

71 Ahmadiyeh N, Stoleru MA, Raza S, Lester SC, Golshan M: Management of intraductal papillomas of the breast: an analysis of 129 cases and their outcome. Ann Surg Oncol 2009;16:2264-2269.

72 Ra YM, Sohn JS, Kim KW, et al.: Clinicopathologic review of the intraductal papilloma of breast. J Breast Cancer 2010;13:31-36.

73 Sauter ER, Ehya H, Schlatter L, MacGibbon B: Ductoscopic cytology to detect breast cancer. Cancer J 2004:10:33-41.

74 Sauter ER, Klein-Szanto A, MacGibbon B, et al.: Nipple aspirate fluid and ductoscopy to detect breast cancer. Diagn Cytopathol 2010;38:244-251.

75 Jung SY, Kang HS, Kwon Y, et al.: Risk factors for malignancy in benign papillomas of the breast on core needle biopsy. World J Surg 2010;34:261-265.

76 Chaudary M, Millis R, Davies G, Hayward J: Nipple discharge: the diagnostic value of testing for occult blood. Ann Surg 1982;196:651-655.

77 Matsunaga T, Kawakami Y, Namba K, et al.: Intraductal biopsy for diagnosis and treatment of intraductal lesions of the breast. Cancer 2004;101:2164 2169 .

78 Dennis MA, Parker S, Kaske TI, et al.: Incidental treatment of nipple discharge caused by benign intraductal papilloma through diagnostic mammotome biopsy. AJR Am J Roentgenol 2000;174: 1263-1268.

79 Torres-Tabanera M, Alonso-Bartolome P, VegaBolivar A, et al.: Percutaneous microductectomy with a directional vacuum-assisted system guided by ultrasonography for the treatment of breast discharge: experience in 63 cases. Acta Radiol 2008; 49:271-276. 